\title{
QUANTITATIVE META-ANALYSIS OF VISUAL MOTIFS THROUGHOUT FILM HISTORY
}

\section{Meta-análisis cuantitativo de los motivos visuales en la historia del cine}

Manuel Garin and Albert Elduque

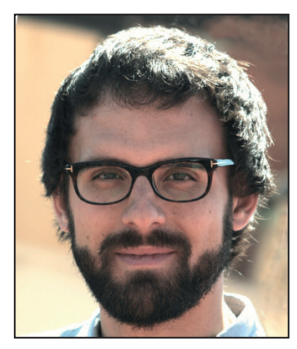

Manuel Garin works at Universitat Pompeu Fabra, where he teaches as a senior lecturer in film and media studies. In 2012 he defended his Ph.D. thesis on visual humor, later published as a book: El gag visual (Cátedra, 2014). He developed research stays at The Tokyo University of The Arts and the University of Southern California, and has published in scientific journals like International journal of cultural studies, Communication \& society or L'Atalante, and contributed to books edited by The MIT Press, ABC-Clio, and Mimesis.

http://orcid.org/0000-0001-9596-8257

Universitat Pompeu Fabra Department of Communication Roc Boronat, 138. 08018 Barcelona, Spain manuel.garin@upf.edu

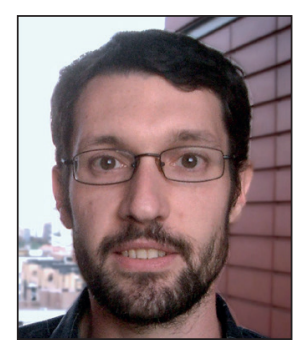

Albert Elduque is a postdoctoral researcher at the University of Reading, where he works in the AHRC/Fapesp-funded project 'Towards an intermedial history of Brazilian cinema: Exploring intermediality as a historiographic method' (Intermldia). His research areas include cinema history, film aesthetics, and intermediality, focusing particularly in European and Latin American political cinema and Brazilian music documentaries. He is a member of the Centre for Aesthetic Research on Audiovisual Media (Cinema), at Universitat Pompeu Fabra, and co-editor of the journal Cinema Comparat/ive Cinema.

http://orcid.org/0000-0002-5194-4525

University of Reading Department of Film, Theatre and Television Minghella Building, Shinfield Road, Reading RG6 6BT (Berkshire), United Kingdom a.elduquebusquets@reading.ac.uk

\begin{abstract}
This paper assesses the importance of visual motifs as new research tools for film and media studies, by running a quantitative meta-study of two expert review databases: the British Film Institute best-movies 2012 poll and the Encyclopedia of visual motifs in cinema (a joint venture of up to sixty researchers and film critics). The former is used as an indicator of canonic values in film historiography, while the latter represents a new approach to cinema from a less hierarchical and nonauteur-oriented methodology. Three main variables are quantified and compared (decades, genres, directors), pointing to a low accordance between the top films of both databases, as well as to noteworthy differences in terms of historical scope, high / low culture values, and authorship.
\end{abstract}

\section{Keywords}

Quantitative research; Databases; Visual motifs; Rankings; Cinema; History; Genres; Film and media studies; Encyclopedia of visual motifs.

\section{Resumen}

El presente artículo analiza la relevancia de los motivos visuales como nuevas herramientas de investigación en cine y comunicación audiovisual, mediante un meta-análisis cuantitativo de dos bases de datos críticas: el ranking de las mejores películas de la historia publicado por el British Film Institute en 2012 y la Enciclopedia Motivos visuales del cine (un proyecto colaborativo de hasta sesenta investigadores y críticos). El primero se utiliza como indicador de valores canónicos de la historiografía cinematográfica, mientras el segundo representa un nuevo acercamiento al cine desde metodologías menos jerárquicas y autorales. Se cuantifican y comparan tres variables estratégicas (décadas, géneros, cineastas), que confirman un nivel de concordancia bajo entre las películas más significativas de ambas bases de datos, y apuntan diferencias notables en cuanto a la perspectiva histórica, los valores de alta y baja cultura y la autoría fílmica. 


\section{Palabras clave}

Investigación cuantitativa; Bases de datos; Motivos visuales; Rankings; Cine; Historia; Géneros; Estudios fílmicos y audiovisuales; Enciclopedia Motivos visuales del cine.

Garin, Manuel; Elduque, Albert (2016). "Quantitative meta-analysis of visual motifs throughout film history". El profesional de la información, v. 25, n. 6, pp. 883-892.

https://doi.org/10.3145/epi.2016.nov.05

\section{Introduction}

The impact of quantitative methods within film history has significantly increased in the last decade, giving birth to a variety of analytical strategies that further enrich cinema and media studies. New and exciting research has blossomed: the most accomplished example is Cinemetrics, the methodology that allows scholars all over the world to quantify the formal and structural variables of movies, from average shot lengths, to editing patterns, framing scales, or camera movement (Salt, 2006; Baxter, 2014); a statistical approach to style currently being used to study diverse content like Japanese animation (Kohara; Niimi, 2013) or soap operas (Butler, 2010, p. 50). Along with that formal perspective, other numerical methods such as the quantification of large-scale movie rating databases are being explored, and humorously enough, medical journals have even published quantifications on the life expectancy of Oscar winners (Sylvestre; Huszti; Hanley, 2006). But, as varied and novel as such initiatives may be, it is legitimate to ask to what extent those methods reinforce already existing practices of valorization and canonic taste in film studies, specifically, auteur-oriented approaches (Buckland, 2008, p. 224). Are those quantitative efforts expanding traditional methods of historiography with new research tools? Or do they reinforce fully institutionalized parameters, and therefore point us to the same old story?

The growing impact of quantitative studies within film history methodologies raises a crucial question: do such quantifications offer new paths that go beyond traditional historiography or do they reinforce institutionalized parameters?

Our goal in this article is to address such claims by sharing the results of a new type of quantitative meta-study focused on visual motifs as new research tools for film history. Instead of quantifying cinema with already established variables like plot keywords (Sreenivasan, 2013) that will surely lead us to already established concepts, we aim to find new ones. Before getting started, though, it is worth mentioning where such an initiative comes from. For the last two years, the Imacs network of film studies (an alliance of thirteen European universities ${ }^{1}$ ) has been developing a collective project called $A$ history of cinema without names, in search of new methodologies that go beyond the traditional auteur-oriented versions of film history. Its goal is to find new ways to conceive and share the history of moving images for new generations of audiences, that is to say, new research parameters that challenge the canonical names already established in film historiography, specifically the "big names" of auteur theory, in an attempt to stress the collective and plural nature of cinema (Cavallotti; Giordano; Quaresima, 2016). Along those lines, this paper uses quantitative metaanalysis in order to accomplish two main goals: test a new analytical tool in film studies methodology (visual motifs) and assess its validity to address film historiography in nonauteur-oriented terms (a history of cinema without names). Can new quantifications point us to new critical challenges?

\section{Visual-motif recurrence as a new research indicator}

To answer that question we have quantified and compared two databases that conceive cinema from different but still comparable perspectives: the 2012 best-films poll of the British Film Institute published by Sight \& sound, which is considered the canonic list by most film scholars and critics worldwide (Christie, 2012); and the Encyclopedia of visual motifs in cinema (EVMC), a joint venture of up to sixty researchers and film critics from five countries who conceived a different type of history based on visual motifs like the horizon, la Pietà, the mirror, or the duel (Balló; Bergala, 2016). Both databases fall within the expert-review method of assessing a film's relevance, as discussed by previous quantitative research (Wasserman; Zeng; Nunes-Amaral, 2014; Canet; Valero; Codina, 2016), but there are noteworthy differences between the two of them. The former, being a poll to begin with, was of course developed from a hierarchical and number-based point of view: hundreds of critics and academics were asked to deliver their all-time top $10 \mathrm{film}$ lists. Whereas the latter is radically qualitative in nature: the contributors had to write brief historical texts about a given motif, adding up to 62 visual motifs in the whole project ${ }^{2}$. In spite of such disparity between the two databases (a list-based ranking vs. a text-based encyclopedia), they both engage in the evaluation of film history by critics and academics, so to a certain extent, they embody the established canon of film history today and a new attempt to rethink it using visual motifs.

The numbers of the $B F I$ ranking are available online, but how about the numbers of the EVMC, the outcome of which is a written book? To quantify this motif database we had to manually process all the mentions to films, authors, and other works within the project, adding up to an archive of more than 13,000 data inputs. Needless to say, such figures could be organized and interpreted in many ways, but for 
the purpose of this article it was key to establish a reliable sample to be compared with the $\mathrm{BFI}$ canonical list. Thus the first step concerned the exact quantification of films mentioned in the encyclopedia, as well as their impact in the history of cinema (without names) they pose.

As Figure 1 shows, the 706 films mentioned in the encyclopedia were later sampled depending on whether each movie reappeared in various texts (meaning in different visual motifs) across the database. A necessary step in order to acquire an aggregated estimate of a particular film's relevance as generator of visual motifs, since the more times a title is mentioned in different entries by different authors, the more statistically relevant it is for a new history of cinema based on visual motifs,

"the aggregation of numerous expert ratings performs better as an indicator of significant films than the ratings of an individual expert" (Wasserman; Zeng; NunesAmaral, 2014, p. 1286).

The resulting stats are plain: 575 films are only mentioned in a single motif, 96 in two visual motifs, 20 in three, 12 in four, and only 3 reappear in more than four visual motifs. Percentage-wise, $81 \%$ of the overall mentioned movies have zero recurrence, while the remaining $19 \%$ reach a higher degree of significance because they evoke different motifs. Although those 131 recurrent films only amount to a fifth of the total database, they nevertheless constitute the center of the encyclopedia's canon and should be regarded as the higher impact data of the whole project. Given that the nearly sixty contributors of the EVMC had complete freedom of choice in terms of how many films they could quote in their text and from which period (Balló; Bergala, 2016, p. 11), it was extremely important to quantify the aggregated values of each film, in order to reduce the (inevitable) bias of any expert-review assessment. That being said, what does the map of visual-motif significance look like?

If the purpose of cloud graphics is to perceive the overall layout of a database, jumping from text to text-collection (Nualart-Vilaplana; Pérez-Montoro; Whitelaw, 2014, p. 231), Figure 2 tells a rather different story than traditional film polls. Top lists like the BFI's produce a hierarchical image that reinforces the betterthan/worse-than logic (Number 1, Number 2, Number 3, etc.), but the above mentioned visual-motif data is organized in a less hierarchical way, dozens of movies share the same recurrence level in the cloud. Only the first three stand in a top-down scale: Vertigo (Alfred Hitchcock, 1958) is quoted in 14 visual motifs across the encyclopedia, distantly followed by another Hitchcock movie, North by Northwest (1959) with six mo-

Figure 2. Cloud visualization of the films that engender more visual motifs 
Visual Motiss Encyclopedia [left] Sight and Sound BFI poll [right]

Vertigo, North by Northwest, Persona

2001, À bout de souffle, Lost Highway, Letter from an Unknown Woman, The Searchers, Battleship Potemkin, Man with a Movie Camera, L'Atalante, Rear Window, Mulholland Drive, Psycho, Une partie de campagne

Germania anno zero, Sunrise, Blow Up, Casablanca, Domicile conjugal, O Estranho Caso de Angélica, The Birth of a Nation, Vale Abraao, Jules et Jim, Gerry, L'avventura, La Maman et la Putain, Metropolis, ParisTexas, Playtime, Rebecca, Roma città aperta, Seven Chances, Spiderman, Life Nothing More
1. Vertigo 2. Citizen Kane 3. Tokyo Story

4. La règle du jeu 5. Sunrise 6. 2001

7. The Searchers 8. Man with a Movie Cam

9. The Passion of Joan of Arc 10. $81 \frac{1}{2}$

11.Potemkin 12. L'Atalante 13. Breathless

14. Apocalypse 15. Late Spring 16. Au hasard

17. Seven Samurai 18. Persona 19. Zerkalo

20. Singin' 21. L'avventura 21. Le Mépris

21. The Godfather 24. Ordet 24. In the Mood

26. Rashomon 26. Andrei Rub 28. Mulholland

29. Stalker 29. Shoah 31. Godfather II 31. Taxi

33. Bicycle 34. The General 35. Metropolis

Figure 3. The $E V M C$ and the $B F I$ top 35 films compared

tifs, and Persona (Ingmar Bergman, 1966) with five. But beyond those three titles, the sampling of films is much more egalitarian because up to 12 movies share the fourth level of visual motif relevance (with 4 motifs each), 20 are equally placed in the fifth level ( 3 motifs each), and an aggregate of 96 movies stand in the sixth degree (2 motifs per film). All this is, of course, related to the size of each database and the visualization of the results, but we think it is worth underlining this difference between a ranking-oriented database such as the $B F I$ list, conceived in top/down and better/worse terms from the beginning, and a text-oriented one like the encyclopedia, the results of which offer a less hierarchical distribution of each movie's importance within the database, and consequently, within film history itself ${ }^{3}$.

The BFI ranking and the Encyclopedia of visual motifs are two databases that fall within the expert-review method of assessing a film's relevance, but there are noteworthy differences between the two of them in terms of a more or less hierarchical approach

\section{Comparison with the $B F I$ canon: two historical paradigms?}

After quantifying the database it was paramount to minimize the range of bias, but how? By ruling out the films that only received two mentions in two visual motifs across the encyclopedia, we minimized the risk of coincidental sampling: two authors (out of sixty) unconsciously choosing the same two films in their respective texts is a possible scenario, but the reappearance of one movie in three different entries by three different authors is a more reliable indicator given the ratio of overall recurrence (one mention $81 \%$, two mentions
$14 \%$, and three or more mentions 5\%). In other words, for a film to generate three or more visual motifs in the database, more things had to be at stake than mere chance. That's why we have chosen to focus our comparison on the 35 top films that acquire the highest critical and visual significance in each database.

The comparative data in Figure 3 highlights the differences between a history of cinema conceived through visual motifs instead of names, on the left, and a ranking-oriented history directly based on canonic names, on the right (abbreviations of the longest titles were necessary for the graphic comparison of the samples). Beyond the fact that Vertigo dominates both lists, only $37 \%$ of the top films coincide, in what should by all means be interpreted as a low figure given that in both databases the contributors were academics and critics, bound to have a similar take on canonic history (very different from popular quantifications such as those found in the IMDb database, as proven by Canet; Valero; Codina, 2016, p. 160). It is worth remembering, though, that the Encyclopedia of visual motifs top 35 is the result of our efforts to quantify a project when the nature of it is qualitative (none of the contributors listed their films from top to bottom as they would do in a poll), and that is precisely why the results are so daring to develop new research methodologies in film studies (Maltby; Biltereyst; Meers, 2011, p. 34).

Comparing the top 35 lists, only 12 films (listed in black) are prime in both databases, the remaining 23 appear exclusively on the BFI top (listed in blue) or, conversely, on the encyclopedia (listed in green). Therefore, films like Battleship Potemkin (S. M. Eisenstein, 1925) or L'avventura (Michelangelo Antonioni, 1960) can be considered canonical both poll-wise and visual-motif-wise, whereas movies like Gerry (Gus Van Sant, 2002) or Letter from an unknown woman (Max Ophüls, 1948) stand out for their visual richness, and on the other side of the spectrum, canonic masterpieces like Rashomon (Akira Kurosawa, 1950) or Andrei Rublev (Andrei Tarkovsky, 1966) don't acquire a high visual-motif recurrence. But, as significant as they may be, the titles of each film can't be read in the quantitative fashion we hereby propose, so an additional set of variables is needed to engage fully with this $\mathrm{BFI}$ / visual-motif comparison. To achieve such a goal, we have quantified both top 35 lists using three main parameters: historical scope (the amount of mentioned films per decade), genre distribution (which generic codes are prevalent), and authorship (which filmmakers are more or less representative). Let's focus on the first of those variables, history.

As far as the historical scope is concerned, the patterns are fairly similar during the 1920-1969 periods, with the slight difference of more films from the 40 s being quoted in the 

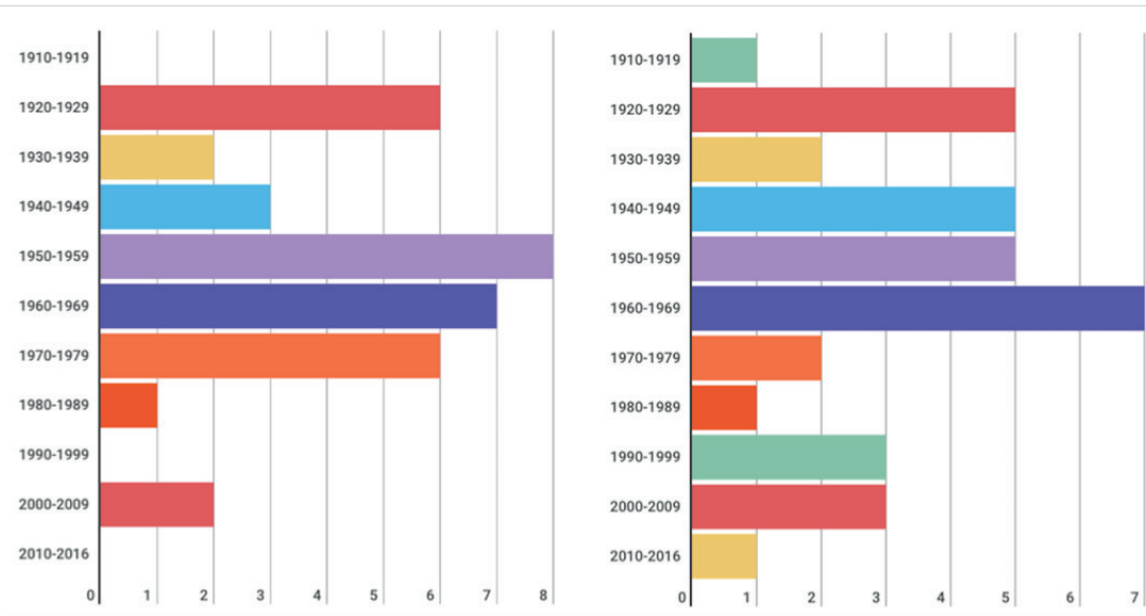

Figure 4. Historical range of $B F I$ poll (left) and EVMC (right)

encyclopedia's top bracket (five to three) and more from the 50s in the poll (eight to five), both decades consecutively balance each other. The 60 s are a highly significant decade in both databases (the highest for visual motifs), because those years mix the mannerism of Hollywood's aging masters with the blossoming of the new waves in Europe, a transformational period with conflicting generations and themes (Font, 2002). But slight differences aside, the comparison changes considerably from 1969 onwards: on the one hand, the impact ratio of the 70s is three times bigger in the BFI poll (six films against two), on the other, the amount of top films after the 70s is almost three times bigger in the Encyclopedia of visual motifs (eight movies against three). Two clear signs of historical discrepancy that point to the same decade and deserve an explanation.

To a certain extent the $B F I$ ranking "ends" film history in the 1970 s, as if movies from the 80s, the 90s, and the 2000s didn't deserve the same canonical status (we shouldn't forget that the poll was published in 2012). A closer look into the specific data confirms that films like The godfather (F. F. Coppola, 1972) and its sequel, or Apocalypse now (F. F. Coppola, 1979) and Taxi driver (Martin Scorsese, 1976), are regarded as the swan songs of film history, a group of masterpieces that attain a degree of significance incomparable to anything produced later on. The New Hollywood Cinema (Biskind, 2003) is statistically the last peak in the evolution of film history, and what comes next does not deserve the same attention (a trend also prevalent in popular databases: Canet; Valero; Codina, 2016, p. 159). Conversely, none of those movies make it to the Encyclopedia of visual motifs (EVMC) top bracket, and what's much more important, after the 70s there is considerable growth of visual-motif impact both in the 90s and in the 2000s. For instance, a movie like Spiderman (Sam Raimi, 2002) could never-ever- rank in the top positions of a $\mathrm{BFI}$ poll, and yet, it nevertheless appears among the most recurrent visual motif films; and for different reasons, the same could be argued about a radically opposed title like $O$ estranho caso de Angélica (Manoel de Oliveira, 2010). A comic-based blockbuster and a less-known auteur film vs. four milestones of the New Hollywood... What is that telling us about both databases?
We think that such an imbalance is due to the flexibility and resilience of visual motifs as tools for film history. Instead of encouraging good/bad or better/worse divides, motifs foster continuity throughout subsequent decades regardless of canonic value. In other words, visual motifs can't "end" in a given historical period, they can't cease to exist just because the movies they appear in are not prestigious enough: visual motifs have to evolve and transform in new ways because film history goes on and audiences keep evolving no matter what (Rosenbaum; Martin, 2003). In the EVMC there is an effort of tracing the evolution of each motif in contemporary cinema after the 80s, beyond the pre-established canon of film historiography. Blatantly different as they are, Spiderman and $O$ estranho caso de Angélica have something in common: they both belong to a post-classical and post-modern era of cinema history where visual motifs are still alive and mutating, in spite of the hierarchies of canonic taste. Thus visual motifs are not only a less hierarchical tool to work with but also expand the historical scope of film history. In order to further explore that hypothesis and assess it with a stronger quantification, we have compared the historical scopes of the encyclopedia's most recurrent films with other analytical variables and samples inside the database.

Only $37 \%$ of the 35 top films coinciding, in what should be interpreted as a low figure given that in both databases the contributors were academics and critics, bound to have a similar take on canonic history

Methodologically, it was important to find out if the historical curve of Figure 4 (related to the 35 top recurrent films) would be analogous in terms of the overall film mentions in the encyclopedia, and as Figure 5 proves, the pattern is very similar. In both the top sample and the whole database, the $60 \mathrm{~s}$ are the decade with a higher amount of mentions ( 8 in the former, 134 in the latter) and in both cases post-70s cinema plays a key role compared with the $B F I$ model: notice the sustained crescendo after the $80 s^{\prime}$ drop, which creates a second historical peak. In fact, Figure 5 confirms that the power of visual motifs as creative evolutions and continuity parameters (history does not end, it mutates) increases in the aggregated total database: the 2000s is actually the third most important decade of all film history in the EVMC, with up to 105 film mentions. In spite of a statistical decrease in the $80 \mathrm{~s}$, also prevalent in the top 35 sample, the amount of total mentions is consistently high through the 90s (91 mentions) and even the 2010s (51 mentions, extremely high for a 2015 project!). 


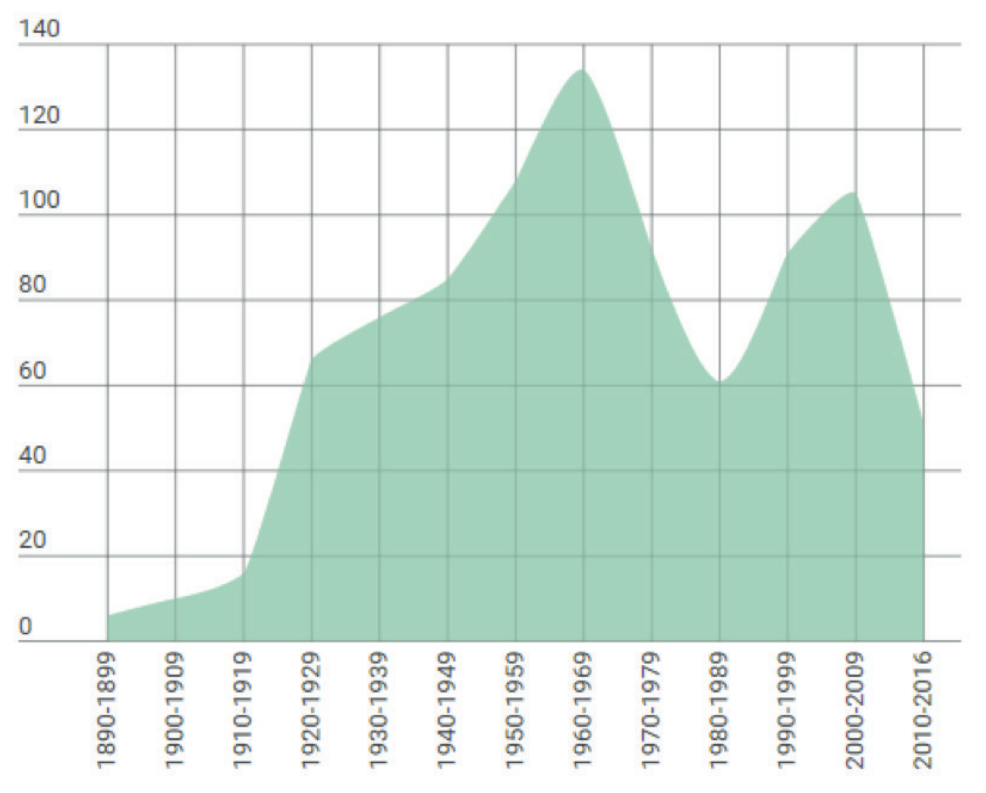

Figure 5. Total film mentions in the Encyclopedia of visual motifs by decades or imbalance we can draw upon the cultural specificity of each database, as proven by previous research quantifications on how genre influences audience reactions (Garza, 2003) or the liaison between genres and the gender-age variable (Redfern, 2012).

Back to our case study, a closer look into Figure 7 confirms a high degree of accordance among lower values: the historical, action, horror, science fiction, comedy, musical, western, and documentary genres show very small differences between the $B F I$ poll and the EVMC, all ranging from 1 to 3 movies per genre within the top 35. As proven by the similar sector patterns of Figure 7 , those genres are almost equivalent in the two databases because the difference of quoted films is below 3\% (1-to-2 or 2-to-3 relations). Even noir movies (in black), the impact of which is a little bit higher than the abovementioned genres, reach the same value of $11.4 \%$ in both samples, leveling

Furthermore, we wanted to compare the quantitative data of Figures 4 and 5 with an additional variable: the historical scope of each visual motif inside the encyclopedia. That is to say, the range between the oldest and the newest films quoted by each critic in each text/motif (the vertical and horizontal parameters in Figure 6). We think this may allow for a deeper understanding of how historical frameworks operate in the compass of each motif, and consequently, find out if there is a consistent pattern among the contributors. As Figure 6 shows, most encyclopedia entries cover approximately eight decades of motif history (the average scope is 79 years), so the importance of post-70s contemporary cinema is equally high: the average latest year being 2004 and the earliest average year being 1924. A vast majority of motifs, represented in the various color lines of Figure 6 , show a diagonal 60 pattern that bridges the silent film period (the 20s) with contemporary cinema (the 2000s), thus confirming the wide historical scope and the contemporary sensibility that visual motifs bring to the equation.

\section{Comparison with the BFI canon: genres and authors}

In order to expand the comparative scope we will now tackle genre affiliations within the two databases. Genre is largely considered as a liquid value difficult to assess, the parameters of which change through history and keep crossbreeding (Altman, 1999). For this reason, any classification of genre, including the one in this article, is debatable and should be interpreted loosely. Still, genre remains as a very useful indicator to evaluate different approaches to film history. By assessing a genre's recurrence

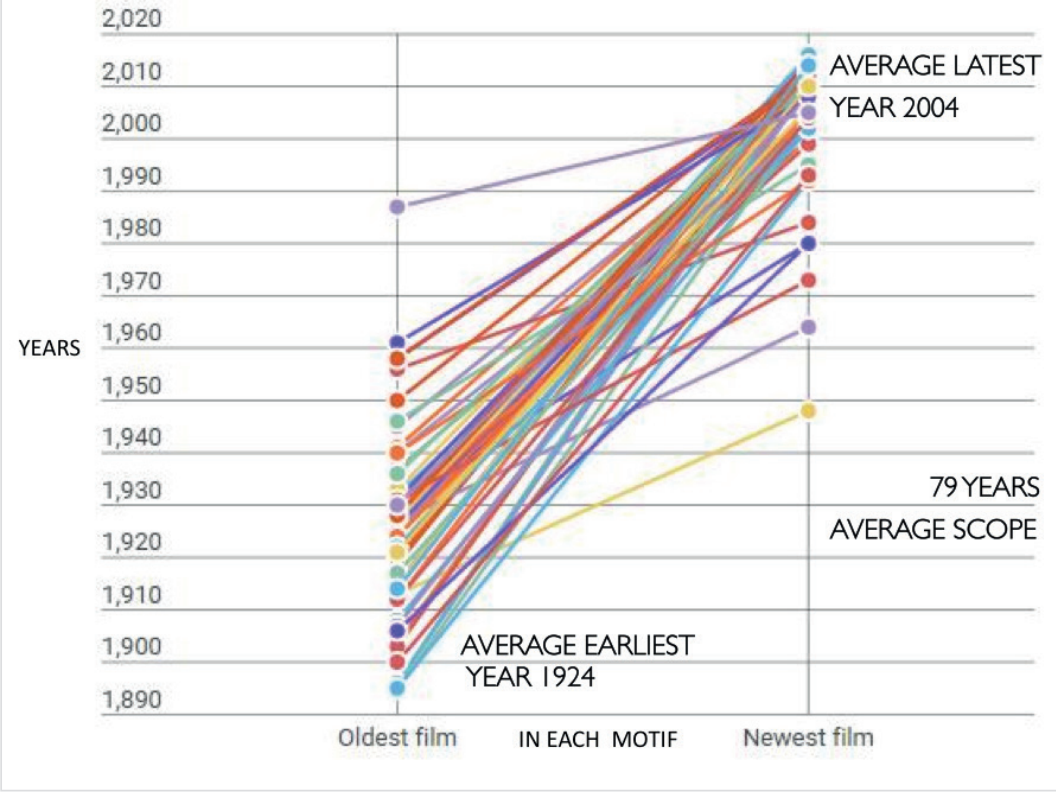

Figure 6. Historical scope between oldest and newest film for each visual motif 
story (Yasujiro Ozu, 1953), Citizen Kane (Orson Welles, 1941), or Ladri di biciclette (Vittorio de Sica, 1948) occupy top ranking positions in the $B F I$ list but do not even appear in the top of the visual motif list.

At the opposite side, the most recurrent genre in the encyclopedia is melodrama, that is to say, drama with romance, love elements, and a higher degree of female protagonists (Mercer, 2004, p. 27). Letter from an unknown woman, Jules et Jim (François Truffaut, 1961), Paris Texas (Wim Wenders, 1984), or Partie de campagne (Jean Renoir, 1936) are very different films that nevertheless share a melodramatic touch, clearly different from the non-romantic gravitas of the abovementioned dramas ${ }^{4}$. It is not only the case that melodrama is more prevalent in the encyclopedia compared with the $\mathrm{BFI}$ poll ( $40 \%$ vs. $22.8 \%$ ), but also that non-romantic prestige drama is much less dominant from a visual-motif perspective (8.6\% vs. $28.6 \%$ ). An imbalance with further implications in terms of the high / low culture values implied by the two databases:

"A comparable oscillation is probably at work between High and Low forms, whose simultaneous existence is a well-known, if often ignored, fact of novelistic history [...] its strength is not to be found in one of the two positions, but in its rhythmical oscillation between them: the novel is not hegemonic because it makes it into High Culture (it does, yes, but it's so desperately professorial to be awed by this fact), but for the opposite reason: it is never only High Culture, and it can keep playing on two tables, preserving its double nature, where vulgar and refined are almost inextricable" (Moretti, 2005, p. 29).

Franco Moretti is one of the scholars who has made best use of quantitative research in the humanities, thanks to his in-depth analysis of literature using numbers, graphics, and maps. We find his comments on the high culture / low culture division close to our comparison, because similar power structures and prestige assumptions hold true for literature and cinema: by substituting the word "novel" for the word "melodrama" in his quote, interesting issues arise. If Moretti quantifies the novel as a flexible literary genre because it is never only High Culture and constantly bridges the vulgar with the refined, we could argue that melodrama plays a rather similar role in relation to prestige drama. Such a high / low culture divide is questionable and rather manichaean, but nevertheless, it runs deep into cinema culture and has remained in the center of debates on film criticism for half a century (Frey, 2013, p. 205). It should not be forgotten why, for decades, the term "melodrama" was extensively used as a derogatory word among critical and academic forums (DeWaard, 2008). Can visual motifs foster a broader conception of historical significance, beyond the highbrow of prestige themes?
It could be argued that the higher ratio of non-romantic dramas in the BFI canon points to a prestige-driven take on film history or, at least, one that celebrates the seriousness and the importance of certain dramatic themes (power, religion, age and class conflicts) above the love struggles of melodrama. Conversely, the EVMC remains closer to that popular genre, which in spite of the "banality" of its love themes generates the richest images and motifs. In a nutshell, and to put it in Renoiresque terms: the BFI poll is a La règle du jeu history, whereas the encyclopedia is a Partie de campagne one. As disputable as this assumption is (it is not clear at all that dramas are always more highbrow than melodramas, neither does it need to be a binary logic), we have pushed this hypothesis a bit further in order to raise pressing questions about the issue at hand. Needless to say, such questions deserve to be fully addressed in further research.

The historical scope of both databases is fairly similar in the 1920-1969 period, but from this point onwards there are crucial discrepancies: the 70s are the last relevant decade in the $B F I$ poll, while the encyclopedia devotes more attention to contemporary developments

Finally, the last parameter worth quantifying is the recurrence of certain filmmakers within both databases. As Pierre Bourdieu pointed out in his monumental study of cultural taste through social and class privilege, the knowledge of directors (their names and their styles) is much more closely linked to cultural capital than is mere cinema-going (Bourdieu, 1996, p. 27). Therefore, it is paramount to have in mind that if the Encyclopedia of visual motifs project is considered an alternative history of cinema without names (in its table of contents there is not a single one, only visual motifs), it is precisely to avoid the auteur-driven cultural capital traditionally linked with film studies. As common as namedropping can be within academic contexts, and as useful as names actually are in pedagogical contexts, in this section we will relate the names of certain filmmakers only to the average mentions of their films within the database, never 
because their "name" is quoted per se. In other words, the quantification and graphic visualization of a given director's importance is hereby derived from the films. We hope that the following paragraphs (full of names) won't blur the nameless logic that ultimately defines this research, even more so given that every single name we quote is derived from visual motifs, not the other way around. That being said, the best way to fully grasp the differences between the encyclopedia and the $\mathrm{BFI}$ poll is to compare cloud distributions of the quantified data.

The most recurrent genre among the encyclopedia's top films is melodrama, whereas the $B F I$ ranking is dominated by serious prestige drama. This imbalance has further implications in terms of the high / low culture values within the two databases

A mere glance on Figure 8 is enough to realize how diverse both databases are in terms of the recurrent filmmakers: the names of Coppola and Tarkovski stand out in the BFI poll, with an aggregated total of 3 films each, whereas in the Encyclopedia of visual motifs the name of Hitchcock immediately captures our attention with 5 of his movies at the top in the 35 visual-motif... adding up to $14.3 \%$ of the sample! The fact that not a single movie by Coppola or Tarkovski makes it to the encyclopedia top bracket, along with the fact that Alfred Hitchcock's movies are five times more significant in terms of visual motifs, proves the considerably distinct approaches to film history of the two databases. The second degree of significance ( 2 films among the top 35) is occupied by completely different names, as a matter of fact, not a single filmmaker ranks that high in both samples: Dreyer, Ozu, Godard and Kurosawa stand in the BFI's second position, while Antonioni, Lynch, Truffaut, Rossellini, and Oliveira do the same in the Encyclopedia. Again, there is statistical evidence of how contemporary cinema (that is to say, our time) plays a key role in the visual motif version of film history, whereas the BFI poll seems to end the progress of cinema history in the 70s: classical directors aside, we are talking about a Coppola-driven approach vs. a Lynch-driven or Oliveira-driven one.
In the first section of this paper, we already discovered that Alfred Hitchcock's films were the most significant (by far) in terms of visual motif recurrence: Vertigo, the most quoted film in the database, is three times more recurrent than the first non-Hitchcock film in the top 35, Persona; and North by Northwest, the second higher impact movie, is two to three times more recurrent than any other top title. As if that were not enough, the director of Psycho (1960) dominates the top recurrence cloud visualization as well as the overall mentions to films in the whole encyclopedia, both in terms of aggregated totals (his films appear 53 times in different entries, doubling the next filmmaker's count) and in terms of title diversity (up to 19 different Hitchcock movies are quoted). Moreover, after quantifying all the names mentioned in the encyclopedia (directors, actors, characters), we established that Hitchcock is the most quoted person and Scottie (from Vertigo) the prime character. On the contrary, in the $\mathrm{BFI}$ poll we have to go beyond the top 35 to find a second Hitchcock movie, in spite of Vertigo occupying the first position. Most certainly, the critics and academics that voted in that poll "refrained" from over-quoting Hitchcock in their lists, perhaps trying to balance film history with more names (a fair and understandable purpose). But that sort of historiographical self-censorship did not happen in the EVMC, since the contributors were free to shape history without requirements or guilty-complexes, just writing about each single motif. So after a thorough quantification of the database, it seems that the popular consensus of Hitchcock being the most visual of filmmakers (Truffaut, $1985)$ is statistically true. ${ }^{5}$

\section{Conclusions and further research}

Exploratory research is bound to reach exploratory conclusions, and that is the nature of this visual motif quantification. Future efforts should undoubtedly expand our bifold comparison to other movie databases and archives, in order to problematize the concept of historical relevance. As consistent as the results are, and as different as film history looks from a visual motif perspective (beyond established auteur theory), we should interpret the data with caution. Especially because the true appeal of the Encyclopedia of visual motifs in cinema (EVMC) is qualitative: it should be read and enjoyed motif-by-motif, not simply judged for this quantification. Still, and considering the two research gaps we promised to fill some pages ago in the introduction (visual motifs as a potentially new research tool, plus a without names database logic) it is only fair to look back at our opening question to answer it. Are visual motifs useful tools to assess the historical significance of films from a less hierarchical and non-auteurdriven standpoint?

Yes, no doubt. But still, further research ought to be

Figure 8. Filmmakers in the BFI poll (left) and the EVMC (right) 
developed in order to reassess the four main conclusions of this meta-analysis. First, the sample of significant films from a visual motif methodology is radically diverse from the outcome of established critical polls such as the BFI list, with a $63 \%$ discordance range among the 35 top movies of both databases (see Figure 3). Secondly, the use of less canonic research tools like visual motifs heightens the variety and continuity of film history from its early decades to contemporary cinema, almost tripling the impact of recent movies -made after the 70s- in the top 35 sample (see Figures 4, 5, and 6); therefore, the visual motif database embraces the current mutations of film culture instead of glorifying golden ages like the BFI list does with the New Hollywood Cinema. The third conclusion has to do with the prestige and high / low culture implications of film genre, as debatable as they may be: a motif-based history seems to be more connected with the high/low ambiguity of melodrama than with the serious gravitas of high drama, pointing to a romantic love-related sensibility closer to popular taste (see Figure 7). Finally, auteur-wise, there are radical differences in the impact of certain filmmakers within the BFI top 35 and the EVMC, with Francis Ford Coppola's films being on top of the former and Alfred Hitchcock's clearly dominating the latter. Because of the novelty (and risk) of this kind of research topic, we sincerely wish that, in spite of the limited scope of our visual-motif quantification, such results will encourage new ways of addressing film history that, hopefully, don't repeat the same old story in disguise.

Alfred Hitchcock's films are the most significant in terms of visual motif recurrence: they have the highest presence across the whole encyclopedia, both in terms of overall mentions and in terms of title diversity

\section{Notes}

1. The Imacs network organizes an International Master in Cinema and Audiovisual Studies as well as a variety of research activities and shared projects that altogether shape a distinguished initiative in the field of cinema and media studies in Europe. The thirteen universities are: Birkbeck College London, Goethe-Universität Frankfurt, Ruhr-Universität Bochum, Universitat Pompeu Fabra Barcelona, Università Cattolica del Sacro Coure Milan, Università degli Studi di Udine, Università degli Studi Roma 3, Université Charles-deGaulle Lille 3, Université de Liège, Université de Montréal, Université de Paris Ouest Nanterre La Défense, Université Sorbonne Nouvelle Paris 3, Universiteit van Amsterdam.

2. The complete list of motifs is: landscapes through the windshield, swing, stairs, exit from work, trail, bed, cat, kiss, house, family meals, alley, siege, scream, abyss, series, camera, screen, duel, hunt, public execution, chase, excavator, sleeping woman, someone wakes up, nape, the woman in the window, mirror, mountain, harvest, tempest, ruins, crowd, letter, mobile phone, clock, bouquet, facing the grave, shadow, ghost, photo album, eye, book, touch, lab- yrinth, horizon, castle, park, set's destruction, scar, drop of tears, hand, stain, a body falls down, river, lake, umbrella, peeping toms, master and pupil, la Pietà, the tree, facing the canvas, a microphone enters the frame.

3. Methodologically, we remain aware of the imbalances of the $\mathrm{BFI}$ and the visual-motif comparison throughout this article, but the lack of other motif-oriented databases based on visual motifs and the undeniably canonic status of the Sight \& sound ranking, make it the best option for comparative purposes. Especially since the goal of this text is to raise critical and methodological questions, not necessarily to answer (all of) them.

4. For the purpose of fostering critical debate about canonic history and visual motifs, in the following paragraphs we will deliberately emphasize the genre differences between serious/prestige drama and love-driven melodrama as well as their high/low culture implications, as relative and debatable as they may be.

5. After this Hitchcockian boutade, we would like to stress the experimental and limited scope of this text in terms of its quantified variables. Other film-related parameters of the Encyclopedia of visual motifs database, such as nationality or gender (key to fully grasp how history is institutionally constructed), remain to be addressed in the future.

\section{References}

Altman, Rick (1999). Film/Genre. London: British Film Institute. ISBN: 9780851707174

Balló, Jordi; Bergala, Alain (2016). Motivos visuales del cine. Barcelona: Galaxia Gutenberg. ISBN: 9788416495504

Baxter, Mike (2014). Notes on cinemetric data analysis. Chicago: Cinemetrics.

http://www.cinemetrics.Iv/dev/Cinemetrics_Book_Baxter.pdf

Biskind, Peter (2003). Easy riders, raging bulls. How the sex-drugs-and-rock'n'roll generation saved Hollywood. New York: Sony Music. ISBN: 0684857081

Bourdieu, Pierre (1996). Distinction. A social critique of the judgment of taste. Cambridge: Harvard University Press. ISBN: 0674212770

https://monoskop.org/images/e/e0/Pierre_Bourdieu_ Distinction_A_Social_Critique_of_the_Judgement_of Taste_1984.pdf

Buckland, Warren (2008). "What does the statistical style analysis of film involve?". Literary and linguistic computing, v. 23, n. 2, pp. 219-230.

https://goo.gl/cOEY1M

https://doi.org/10.1093/Ilc/fqm046

Butler, Jeremy (2010). Television style. New York: Routledge. ISBN: 9780415965125

Canet, Fernando; Valero, Miguel-Ángel; Codina, Lluís (2016). "Quantitative approaches for evaluating the influence of films using the IMDb database". Communication \& society, v. 29, n. 2, pp. 151-172.

https://doi.org/10.15581/003.29.2.151-172 
Cavallotti, Diego; Giordano, Federico; Quaresima, Leonardo (2016). A history of cinema without names. Milano: Mimesis International. ISBN: 9788869770302

Christie, Ian (ed.) (2012). "The top 50 greatest films of all time". Sight \& sound, v. 22, n. 9.

DeWaard, Andrew (2008). "The geography of melodrama, the melodrama of geography: The 'hood film's spatial pathos". Cinephile, v. 4.

http://cinephile.ca/archives/volume-4-post-genre/thegeography-of-melodrama-the-melodrama-of-geography-thehood-films-spatial-pathos

Font, Domènec (2002). Paisajes de la modernidad: cine europeo, 1960-1980. Barcelona: Paidós. ISBN: 9788449312250

Frey, Mattias (2013). "The critical question: Sight and sound's postwar consolidation of liberal taste". Screen, v. 54, n. 2, pp. 194-217.

https://doi.org/10.1093/screen/hjt002

Garza, Steven-David (2003). The influence of movie genre on audience reaction to product placement. Thesis in mass communications. Texas Tech University.

http://citeseerx.ist.psu.edu/viewdoc/download?doi=10.1.1. 844.3242\&rep=rep1\&type $=p d f$

Kohara, Itsutoshi; Niimi, Ryosuke (2013): "The shot length styles of Miyazaki, Oshii, and Hosoda: A quantitative analysis". Animation: An interdisciplinary journal, v. 8, n. 2, pp. 163-184. https://doi.org/10.1177/1746847713487472

Maltby, Richard; Biltereyst, Daniel; Meers, Philippe (2011). Explorations in new cinema history: Approaches and case studies. Chichester: Wiley-Blackwell. ISBN: 9781405199490

Mercer, John (2004). Melodrama: Genre, style, sensibility. London: Wallflower. ISBN: 9781904764021

Moretti, Franco (2005). Graphs, Maps, Trees. New York: Ver-

\section{so. ISBN: 9781844670260}

Nualart-Vilaplana, Jaume; Pérez-Montoro, Mario; Whitelaw, Mitchell (2014). "How we draw texts: A review of approaches to text visualization and exploration". El profesional de la información, v. 23, n. 3, pp. 221-235. http://dx.doi.org/10.3145/epi.2014.may.02

Redfern, Nick (2012). "Correspondence analysis of genre preferences in UK film audiences". Participations, v. 9, n. 2. http://www.participations.org/Volume\%209/Issue $\% 20$ 2/4\%20Redfern.pdf

Rosenbaum, Jonathan; Martin, Adrian (eds.) (2003). Movie mutations: The changing face of world cinephilia. London: British Film Institute. ISBN: 9780851709833

Salt, Barry (2006). Moving into pictures: More on film history, style and analysis. London: Starword. ISBN: 978 0950906645

Screenivasan, Sameet (2013). "Quantitative analysis of the evolution of novelty in cinema through crowdsourced keywords". Scientific reports, n. 3, art. 2758.

http://dx.doi.org/10.1038/srep02758

Sylvestre, Marie-Pierre; Huszti, Ella; Hanley, James A. (2006). "Do Oscar winner live longer than less successful peers? A reanalysis of the evidence". Annals of internal medicine, v. 145, n. 5, pp. 361-363.

http://dx.doi.org/10.7326/0003-4819-145-5-200609050-00009

Truffaut, François (1985). Hitchcock / Truffaut. New York: Simon and Schuster. ISBN: 9780671604295

Wasserman, Max; Zeng, Xiao-Han; Nunes-Amaral, Luís A. (2014). "Cross-evaluation of metrics to estimate the significance of creative works". In: Proceedings of the National Academy of Sciences of the United States of America, pp. 1-6. http://dx.doi.org/10.1073/pnas.1412198112

\section{RecBib}

Información sobre empleos, cursos, oposiciones, noticias, eventos y más cosas del mundo de las bibliotecas, archivos, documentación e información ¡Descúbrenos!

www.recbib.es f fb.me/recbib @recbib 